Fourth International Conference on Sustainable Construction Materials and Technologies http://www.claisse.info/Proceedings.htm

SCMT4

Las Vegas, USA, August 7-11, 2016

\title{
Properties of Alkali-Activated Natural Pozzolan and Fly Ash Mortars: A Comparative Study
}

\author{
Meysam Najimi ${ }^{1 a}$, Nader Ghafoori ${ }^{1 b}$, Brittany Radke ${ }^{1 c}$, Kimberly Sierra ${ }^{1 d}$, and \\ MohammadReza Sharbaf ${ }^{1 e}$
}

${ }^{1}$ Department of Civil and Environmental Engineering and Construction, University of Nevada Las Vegas, 4505 Maryland Parkway, Las Vegas, Nevada, USA, 89154-4015.

${ }^{1 a}$ Email: <najimim@unlv.nevada.edu>, ${ }^{l b}$ Email: <nader.ghafoori@unlv.edu >,

${ }^{1 c}$ Email: <radkeb4@unlv.nevada.edu>, ${ }^{1 d}$ Email: < sierrak@unlv.nevada.edu>,

${ }^{1 e}$ Email: <sharbaf@unlv.nevada.edu>

\begin{abstract}
The study presented herein compares flow, strength and transport properties of natural pozzolan- and fly ash-based alkali-activated mortars. To this end, several mixtures were made having natural Pozzolan or fly ash as a binder and sodium hydroxide with different concentrations of $2.5,5,7.5,10$ and $12.5 \mathrm{M}$ as alkaline activator. The produced mortar samples were sealed-cured for 3 hours at $60^{\circ} \mathrm{C}$, and then demolded and sealed-cured at $80^{\circ} \mathrm{C}$ till time of testing. Multiple tests were conducted on alkali-activated mortars including flow spread, compressive strength, flexural strength, elastic modulus, absorption, and rapid chloride migration. These tests were also conducted on Portland cement mortars to compare performance of alkali-activated to that of Portland cement mortars. The results of this study revealed that natural Pozzolan can be activated and perform to the same level of fly ash. However, the rate of activation was slower and the minimum level of alkaline concentration for a proper activation was higher for natural Pozzolan than fly ash. While alkali-activated mortars displayed considerably lower strength than those of Portland cement mortars, the studied mortars activated with sodium hydroxide molarities of 7.5 to $12.5 \mathrm{M}$ produced results suitable for structural applications. The transport properties of alkali-activated mortars having high $\mathrm{NaOH}$ molarity were similar to that of Portland cement mortars.
\end{abstract}

\section{INTRODUCTION}

In recent decades, climate change, due to greenhouse gas emissions, has become a major global issue. Higher temperatures, changing landscapes, rising seas, increased risk of drought, fire and floods, wildlife at risk, stronger storms and increased storm damages, and economic losses are only examples of climate change impact.

One of the main industries responsible for greenhouse gas emissions is cement and concrete industry. Production of Portland cement (PC), as a main ingredient of concrete, contributes to about 7\% of world's total carbon dioxide gas emission [Huntzinger et al. 2009; Pacheco-Torgal et al. 2012]. The desire to 
reduce $\mathrm{CO} 2$ emission of cement production has given impetus to search for new binders including alkaliactivated binders, calcium aluminates cements, calcium carbonate cements, magnesium oxy-carbonate cements, Bellite-calcium sulphoaluminate-ferrite cements, and partially pre-hydrated C-S-H based binders [Pacheco-Torgal et al. 2008; Ismail et al. 2014]. Although far more research is needed for these alternative binders, several researchers suggested that alkali-activated binders may have the potential to lead the transition to the cement of the future [Palomo et al. 1999; Pacheco-Torgal et al. 2008 and 2012; Shi et al. 2011; Ismail et al. 2014]. Accordingly, a great portion of research has recently been devoted on assessment and development of alkali-activated materials.

Fly ash is one of the most popular choices as the starting ingredient of alkali-activated materials. In recent decades, several studies have been dedicated to alkali activation of fly ash. It has been proven that strong and durable mixtures can be made by use of alkali-activated fly ash as the main binder [FernandezJimenez et al. 2006; Pacheco-Torgal et al. 2008]. Various models have also been proposed describing the activation process of fly ash-based geopolymers [Glukhovsky 1994; Fernandez-Jimenez et al. 2005; Palomo et al. 2005; Duxson et al. 2007; Shi et al. 2011].

Natural Pozzolan is another source of aluminosilicates that has similar characteristics to fly ash. Unlike fly ash, the research on alkali-activation of natural Pozzolans has been very limited. Figure 1 compares the number of publications on alkali-activation of natural Pozzolan and fly ash. It can be seen that the research on alkali-activated natural Pozzolan or natural Pozzolan-based geopolymer hardly reaches $2 \%$ of the total studies conducted on alkali-activated fly ash and fly ash-based geopolymer. Figure 2 shows that while it's estimated that about $5 \%$ of the solid surface of the earth is covered by volcanic or effusive rocks (according to Lorenz (1985)), only a few studies have been carried out by a few researchers; mainly in the Middle East [Bondar et al. 2011, 2012; Lemougna et al. 2011; Haddad and Alshbuol 2016]. Moreover, not only the research on activation of natural Pozzolans is limited, there has not been any study to compare properties of natural Pozzolan- and fly ash-based geopolymers.

This study aims to (1) investigate if natural Pozzolan can be successfully activated to meet the desired performance, (2) examine whether natural Pozzolan can be activated to the same level of fly ash by comparing properties of alkali-activated natural Pozzolan and fly ash mortars, and (3) compare properties of alkali-activated mortars with those of Portland cement mortars. To this end, a total of ten natural Pozzolan and fly ash mortars activated with sodium hydroxide concentrations of 2.5, 5, 7.5, 10 and $12.5 \mathrm{M}$, and two reference Portland cement mortars were prepared and their fresh and hardened properties evaluated.

\section{EXPERIMENTAL PROGRAM}

\section{Materials}

The materials used in this study included natural Pozzolan and fly ash as the binder, sodium hydroxide solution as the alkaline activator, and fine aggregates. Type V Portland cement was also used to make reference Portland cement mortars. The chemical properties of the used binders are presented in Table 1. Table 2 documents the chemical and physical requirements of natural Pozzolan and fly ash based on ASTM C618. As can be seen, the used natural Pozzolan and fly ash contained 78.4 and $87.3 \%$ of Pozzolanic oxides (silica, alumina, and iron oxides), respectively, well beyond $70 \%$ requirement of ASTM C618. The used fly ash, however, contained more Pozzolanic oxides than the used natural Pozzolan. The silica-to-alumina ratio of natural Pozzolan was significantly higher than that of fly ash. This ratio was 8.1 for natural Pozzolan; three times as much as that of fly ash (2.7). The calcium oxide content was low for both natural Pozzolan and fly ash (3.2 and 4.7\% for natural Pozzolan and fly ash, respectively), indicating that the used aluminosilicate sources were not cementitious on their own. The fine aggregates used in this study had an oven-dry specific gravity of 2.76 , absorption of $0.81 \%$, and fineness modulus of 2.64 . 


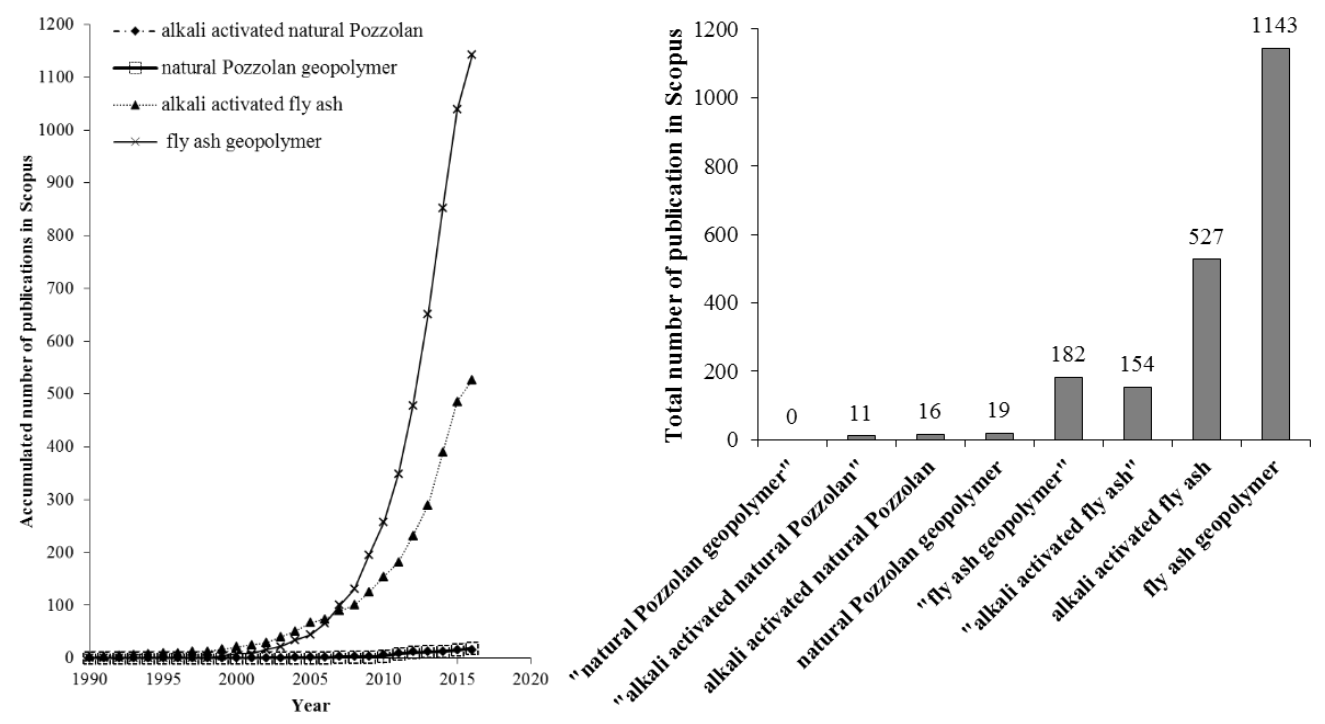

Figure 1. Evolution of accumulated number of publications in Scopus database searched by different keywords in the "article title, abstract, keywords" section

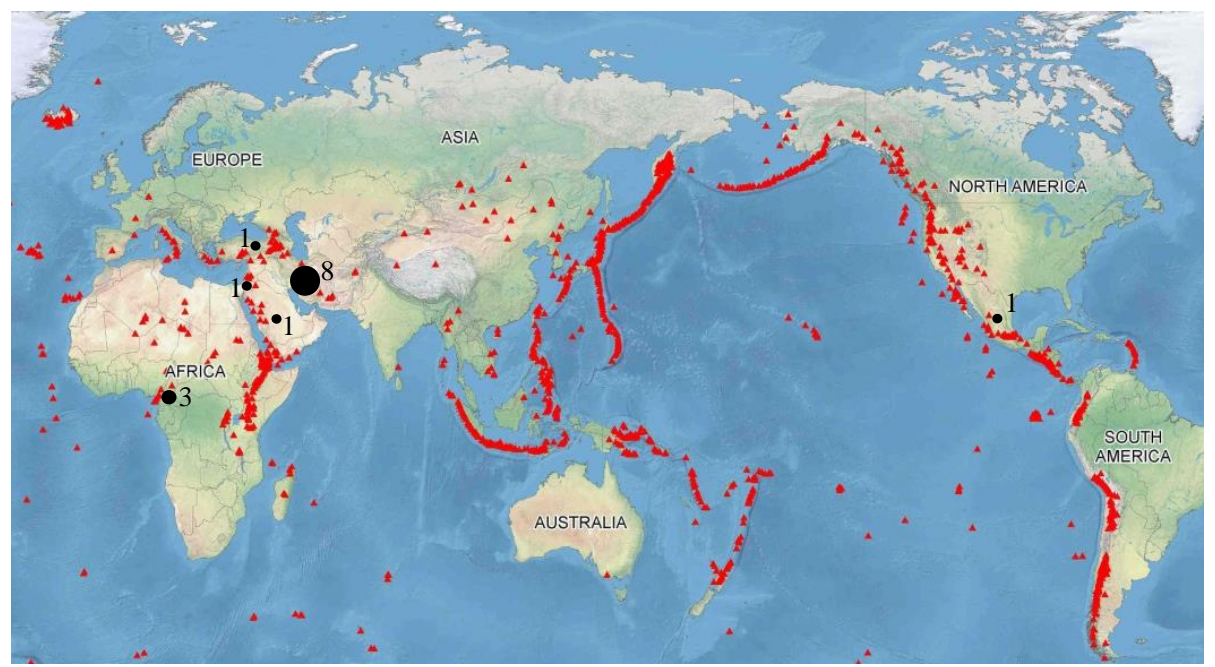

Figure 2. The global map of volcanoes (red triangular) [Sam 2015] and the countries conducted research on alkali-activated natural Pozzolans (black circles)

Sodium hydroxide solutions were made by dissolving $\mathrm{NaOH}$ pellets in distilled water. In order to make a liter of solution with molarities of $2.5,5,7.5,10$, and $12.5 \mathrm{M} ; 100,200,300,400$, and $500 \mathrm{~g}$ of $\mathrm{NaOH}$ pellets were dissolved in enough water to produce one total liter of solution, respectively. The amounts of water and $\mathrm{NaOH}$ used to make a liter of solution are shown in Table $3 . \mathrm{NaOH}$ pellets were added in incremental amounts and underwent vigorous swirling to ensure complete dissolution throughout the distilled water. The $\mathrm{NaOH}$ solutions were allowed to cool down in a water bath before being added to the mortar mixture. 


\section{Mixture proportion}

Table 3 presents the mixture proportion of the selected alkali-activated mortars. This Table includes 5 different mixtures for each binder using sodium hydroxide concentrations of $2.5,5,7.5,10$, and $12.5 \mathrm{M}$, and an activator (solution hydroxide solution)-to-binder ratio of 0.50 (except for mix N12.5 which has a ratio of 0.54 ). For these mixtures, the fine aggregate-to-binder ratio was kept constant at 2 . This ratio was chosen based on a preliminary study conducted on different fine aggregate-to-binder ratios of 1.5, 2, 2.5, and 3. Table 3 also includes two reference Portland cement mortars which were made for comparison purposes. Mixture Reference I was designed in accordance with ASTM C109 (2002) having water-tocement ratio of 0.485 and fine aggregate-to-cement ratio of 2.75. Mixture Reference II was designed by use of similar water-to-cement ratio of 0.485 but different fine aggregate-to-cement ratio of 2 .

\section{Sample preparation}

A single axis industrial pan mixer was used to prepare fresh mortars. Mortar mixtures were prepared by adding one-half of the $\mathrm{NaOH}$ solution in the mixing bowl, followed by carefully adding in the binders and fine aggregates. It was found that adding the $\mathrm{NaOH}$ solution first allowed for easier and more thorough mixing. The fine aggregates, binder, and $\mathrm{NaOH}$ solution were mixed for two minutes on the slow speed (140 $\pm 5 \mathrm{r} / \mathrm{min}$ according to ASTM C305 (ASTM 1999). The remaining one-half of the $\mathrm{NaOH}$ solution was added and the mortar was mixed on the slow speed for an additional two minutes before turning on medium speed (285 $\pm 10 \mathrm{r} / \mathrm{min}$ according to ASTM C305 (ASTM 1999)) for thirty seconds to ensure that the materials were uniformly mixed. Similar method of mixing was used for reference mortars with the exception that all the water was charged to the mixer first. Fresh mortars were tested for flow according to ASTM C1437 (ASTM 2001) before cube, disk and beam-shaped specimens were cast for assessments of compressive strength, absorption, rapid chloride migration and flexural strength.

Alkali-activated mortar samples were sealed-cured initially at $60^{\circ} \mathrm{C}$ for 3 hours in an oven prior to demolding. Samples were then removed from the molds and sealed-cured at $80^{\circ} \mathrm{C}$ till time of testing. The sealed curing was provided by wrapping samples in plastic to retain moisture within the sample. Reference Portland cement mortar samples were left in laboratory for a day before demolding. They were then demolded and transferred to the curing room (ambient temperature and 100\% relative humidity). They were kept in the curing room till testing time.

Table 1. Chemical composition of the used binders

\begin{tabular}{|l|l|l|l|}
\hline Chemical analysis, $\%$ & Cement & Natural Pozzolan & Fly ash \\
\hline Calcium oxide $(\mathrm{CaO})$ & 63.31 & 3.2 & 4.67 \\
\hline Silica $\left(\mathrm{SiO}_{2}\right)$ & 20.42 & 68.8 & 59.93 \\
\hline Alumina $\left(\mathrm{Al}_{2} \mathrm{O}_{3}\right)$ & 4.25 & 8.5 & 22.22 \\
\hline Iron oxide $\left(\mathrm{Fe}_{2} \mathrm{O}_{3}\right)$ & 4.05 & 1.1 & 5.16 \\
\hline Magnesium oxide $(\mathrm{MgO})$ & 2.0 & -- & \\
\hline Sodium oxide $\left(\mathrm{Na}_{2} \mathrm{O}\right)$ & 0.04 & 2.6 & $1.29 *$ \\
\hline Potassium oxide $\left(\mathrm{K}_{2} \mathrm{O}\right)$ & 0.69 & 3.9 & \\
\hline Sulfur trioxide $\left(\mathrm{SO}_{3}\right)$ & 2.98 & 0.1 & 0.38 \\
\hline Loss on ignition & 2.5 & 3.7 & 0.32 \\
\hline
\end{tabular}

* Total alkali, as $\mathrm{Na}_{2} \mathrm{O}$ 
Table 2. Chemico-physical properties of natural Pozzolan and fly ash according to ASTM C618 (2012)

\begin{tabular}{|c|c|c|c|c|c|}
\hline \multicolumn{4}{|l|}{ Requirements } & \multirow{2}{*}{$\begin{array}{l}\text { Natural } \\
\text { Pozzolan } \\
\text { results } \\
\end{array}$} & \multirow{2}{*}{$\begin{array}{l}\text { Fly } \\
\text { ash } \\
\text { results }\end{array}$} \\
\hline & & Class $\mathrm{N}$ & Class F & & \\
\hline \multirow{4}{*}{$\begin{array}{l}\text { Chemical } \\
\text { requirements }\end{array}$} & $\mathrm{SiO}_{2}+\mathrm{Al}_{2} \mathrm{O}_{3}+\mathrm{Fe}_{2} \mathrm{O}_{3}, \%$ & $\min , 70.0$ & $\min , 70.0$ & 78.4 & 87.31 \\
\hline & Sulfur trioxide $\left(\mathrm{SO}_{3}\right), \%$ & $\max , 4.0$ & $\max , 5.0$ & 0.1 & 0.38 \\
\hline & Moisture content, $\%$ & $\max , 3.0$ & $\max , 3.0$ & 0.7 & 0.04 \\
\hline & Loss on ignition, $\%$ & $\max , 10.0$ & $\max , 6.0$ & 3.7 & 0.32 \\
\hline \multirow{6}{*}{$\begin{array}{l}\text { Physical } \\
\text { requirements }\end{array}$} & $\begin{array}{l}\text { Amount retained when wet-sieved on } 45 \\
\mu \mathrm{m} \text { sieve, } \%\end{array}$ & $\max , 34$ & $\max , 34$ & 13.5 & 21.2 \\
\hline & $\begin{array}{l}{ }^{1} \text { Strength activity index, at } 7 \text { days, } \\
\text { percent of control }\end{array}$ & $\min , 75$ & $\min , 75$ & 85 & 83 \\
\hline & $\begin{array}{l}{ }^{1} \text { Strength activity index, at } 28 \text { days, } \\
\text { percent of control }\end{array}$ & $\min , 75$ & $\min , 75$ & 92 & 79 \\
\hline & Water requirement, percent of control & $\max , 115$ & $\max , 105$ & 103 & 97 \\
\hline & Autoclave expansion or contraction, $\%$ & $\max , 0.8$ & $\max , 0.8$ & 0 & -0.02 \\
\hline & Specific gravity & -- & -- & 2.29 & 2.31 \\
\hline
\end{tabular}

${ }^{I}$ Note that, the activity index is determined based on ASTM C311 (2013) by replacing $20 \%$ of cement with natural Pozzolan or fly ash.

Table 3. Mixture proportions and flow of alkali-activated and Portland cement mortars.

\begin{tabular}{|c|c|c|c|c|c|c|c|c|}
\hline \multicolumn{9}{|c|}{ Alkali-activated mortars } \\
\hline \multirow[t]{2}{*}{ Mix id } & \multirow{2}{*}{$\begin{array}{l}\text { Activator } \\
\text { Molarity }\end{array}$} & \multirow{2}{*}{$\begin{array}{l}\text { Fly ash } \\
\text { (g) }\end{array}$} & \multirow{2}{*}{$\begin{array}{l}\text { Natural } \\
\text { pozzolan } \\
(\mathrm{g})\end{array}$} & \multirow{2}{*}{$\begin{array}{l}\text { Fine } \\
\text { Aggregate } \\
\text { (g) }\end{array}$} & \multirow{2}{*}{$\begin{array}{l}\text { Activator } \\
\text { Solution } \\
\text { (g) }\end{array}$} & \multicolumn{2}{|c|}{$\begin{array}{l}\text { Weight per liter of } \\
\text { solution }(\mathrm{g})\end{array}$} & \multirow{2}{*}{ Flow $(\mathrm{cm})$} \\
\hline & & & & & & Water & $\begin{array}{l}\text { Sodium } \\
\text { Hydroxide }\end{array}$ & \\
\hline $\mathrm{N} 2.5$ & \multirow{2}{*}{2.5} & 0 & 4740.3 & \multirow{2}{*}{9480.6} & \multirow{2}{*}{2370.2} & \multirow{2}{*}{989.1} & \multirow{2}{*}{100} & 9.9 \\
\hline F2.5 & & 4740.3 & 0 & & & & & $15.2^{*}$ \\
\hline N5 & \multirow{2}{*}{5} & 0 & 4740.3 & \multirow{2}{*}{9480.6} & \multirow{2}{*}{2370.2} & \multirow{2}{*}{973.9} & \multirow{2}{*}{200} & 6.5 \\
\hline F5 & & 4740.3 & 0 & & & & & $15.2^{*}$ \\
\hline $\mathrm{N} 7.5$ & \multirow{2}{*}{7.5} & 0 & 4740.3 & \multirow{2}{*}{9480.6} & \multirow{2}{*}{2370.2} & \multirow{2}{*}{950.3} & \multirow{2}{*}{300} & 5.7 \\
\hline F7.5 & & 4740.3 & 0 & & & & & 12.1 \\
\hline N10 & \multirow{2}{*}{10} & 0 & 4740.3 & \multirow{2}{*}{9480.6} & \multirow{2}{*}{2370.2} & \multirow{2}{*}{903.4} & \multirow{2}{*}{400} & 3.7 \\
\hline F10 & & 4740.3 & 0 & & & & & 11.8 \\
\hline $\mathrm{N} 12.5^{* *}$ & \multirow{2}{*}{12.5} & 0 & 4740.3 & \multirow{2}{*}{9480.6} & $2559.8^{* *}$ & \multirow{2}{*}{858.8} & \multirow{2}{*}{500} & 3.5 \\
\hline F12.5 & & 4740.3 & 0 & & 2370.2 & & & 8.5 \\
\hline \multicolumn{9}{|c|}{ Reference Portland cement mortars } \\
\hline \multicolumn{2}{|c|}{ Mix id } & \multicolumn{2}{|c|}{ Cement (g) } & Fine Aggre & ate $(\mathrm{g})$ & Water & & Flow $(\mathrm{cm})$ \\
\hline Referenc & & 4740.3 & & 13035.8 & & 2299 & & 15.2 \\
\hline Referenc & e II & 4740.3 & & 9480.6 & & 2299 & & $15.2^{*}$ \\
\hline
\end{tabular}

* These flows were higher, but the test apparatus only allowed for flow measurement of up to $15.2 \mathrm{~cm}$.

** As flow of mix N12.5 was extremely low using activator-to-binder ratio of 0.5 (impractical to cast), this ratio was increased to 0.54 for this mixture. 


\section{Testing}

The flow test was conducted according to ASTM C1437 (ASTM 2001) upon batching.

Compressive strength test was performed on $5 \mathrm{~cm}$ cube samples in a procedure similar to ASTM C109 (ASTM 2002b).

The flexural strengths of the $5 \times 5 \times 20 \mathrm{~cm}$ beams were measured in accordance with ASTM C78 (ASTM 2002a). Four beams were tested for each mixture. Strain gauges were attached to the extreme tension side of the beams to determine strain and modulus of elasticity.

Absorption and volume of permeable voids were measured according to ASTM C642 using disks with diameter of $10 \mathrm{~cm}$ and height of $5 \mathrm{~cm}$. Similar size disks were used for measurement of rapid chloride migration in accordance with NT BUILD 492 (1999).

\section{RESULTS AND DISCUSSIONS}

\section{Flow}

The results of the flow test are presented in Table 3. As can be seen, the flow of alkali-activated natural Pozzolan mortars were significantly lower than those of alkali-activated fly ash mortars. On average, the flow of natural Pozzolan-based mortars was 54.5\% lower than that of fly ash-based mortars. This difference could have been even higher if the flow table allowed for measurements of more than $15.2 \mathrm{~cm}$ and mix N12.5 could be mixed with activator-to-binder ratio of 0.50 . The observed difference can be related to the finer particle size of natural Pozzolan as compared with fly ash (See Figure 3). The median particle size (50\% passing size) of natural Pozzolan was almost 15.8 micron which was lower than that of fly ash (20 micron). Table 2 also shows that the used natural Pozzolan had higher water demand than the used fly ash. The finer particle size and higher water demand of natural Pozzolan led to lower flow of alkali-activated natural Pozzolan mortars than companion fly ash mortars.

The flow of both types of alkali-activated mortars was lower than that of Portland cement mortars. On average, the flow of natural Pozzolan- and fly ash-based mortars were 61 and 17\% lower than that of Portland cement mortars, respectively. Some of the fly ash-based mortars (2.5 and 5M), however, had a similar flow to those of the reference mortars.

The flow of alkali-activated mortars decreased when $\mathrm{NaOH}$ concentration increased. The decreases in flow of natural Pozzolan-based mortars were 34, 12, and 35\%, when molarity of activator increased from 2.5 to 5,5 to 7.5 , and 7.5 to 10 , respectively. In case of alkali-activated fly ash mortars, the flow reduced by $20,2.5$, and $28 \%$ when molarity increased from 5 to $7.5,7.5$ to 10 , and 10 to 12.5 , respectively. An explanation for this trend can be due to the amount of alkaline and water in the prepared solution. An increase in the activator concentration allowed for more sodium hydroxide pellets and less free water for a given volume, resulting in the reduction of flow spread.

\section{Compressive strength}

Table 4 documents the results of the compressive strength test for all the tested mixtures. Overall, $2.5 \mathrm{M}$ was insufficient for activation of either natural Pozzolan or fly ash resulting in considerably low strengths. Higher sodium hydroxide concentration was required for proper activation of natural Pozzolan as compared with fly ash. Considering $20 \mathrm{MPa}$ as a minimum strength requirement for structural applications, at least 7.5M was required for activation of natural Pozzolan, whereas $5 \mathrm{M}$ was sufficient for fly ash-based mortars. These observations can be related to the minimum alkalinity required to break the bonds of the starting material. When alkalinity of the system was low, the ionic strength generated in the binder-activator system was not high enough to properly hydrolyze the silicon and aluminum present in the binder [Pacheco-Torgal et al. 2015]. This, in turn, resulted in low strengths. In addition, Si-O bonds 
are stronger than Al-O bonds, thus requiring stronger activator to break their bonds. As silica/alumina was higher for natural Pozzolan than fly ash (Si-O/Al-O bonds of natural Pozzolan > Si-O/Al-O bonds of fly ash), higher alkaline concentration was needed to break the bonds for natural Pozzolan than fly ash.

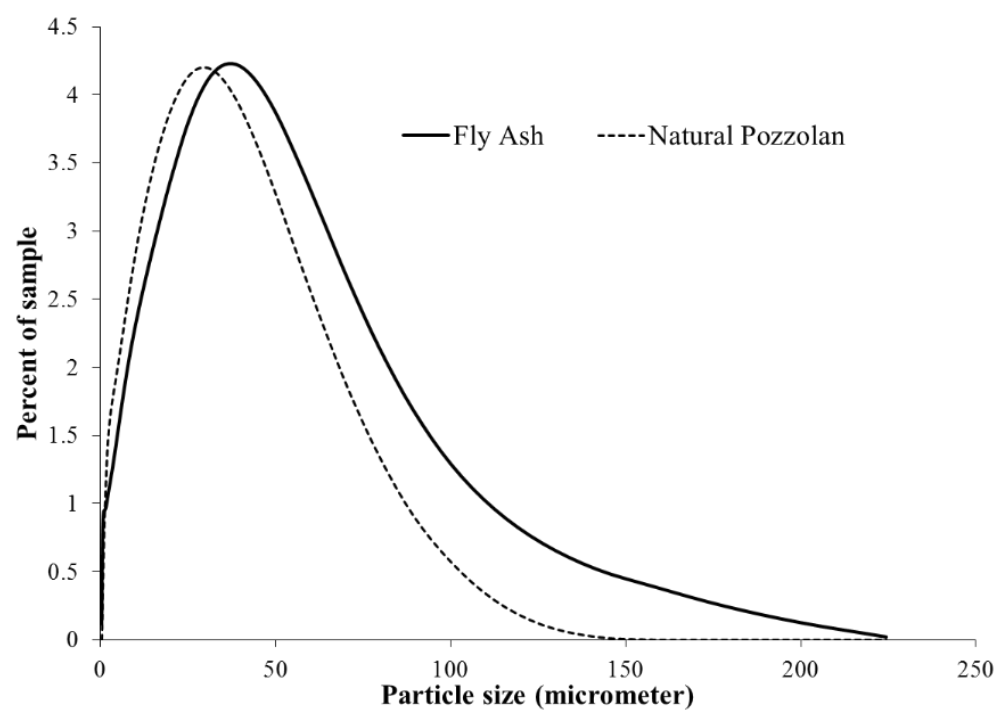

Figure 3. Particle size distribution of fly ash and natural Pozzolan

Alkali-activated fly ash mortars developed higher strengths than alkali-activated natural Pozzolan mortars prepared with lower $\mathrm{NaOH}$ molarities $(5$ and $7.5 \mathrm{M})$. However, the gap in strength between the two alkaliactivated mortars narrowed once high $\mathrm{NaOH}$ concentrations (i.e., 10 and $12.5 \mathrm{M}$ ), were used. The 7-day strengths of natural Pozzolan contained mortars were 39 and $23 \%$ lower than that of fly ash contained mortars activated using $\mathrm{NaOH}$ molarities of 5 and $7.5 \mathrm{M}$, respectively. The strength of $10 \mathrm{M}$ natural Pozzolan contained mortar was slightly higher than that of $10 \mathrm{M}$ fly ash contained mortar (only 5\%). This observation can also be attributed to the minimum level of alkaline needed to break the bonds of the starting material. When alkalinity was more than the abovementioned levels, the activator was able to break Si-O and Al-O bonds for both fly ash and natural Pozzolan even when it could take more time to break the stronger bonds (Si-O) than the weaker bonds (Al-O). In case of $12.5 \mathrm{M}$, natural Pozzolan-based mortar developed $11 \%$ lower strength than fly ash-based mortar. This difference was related to the difference in activator-to-binder ratio. Strength of $12.5 \mathrm{M}$ alkali-activated natural Pozzolan mortar could have been closer to alkali-activated fly ash mortar, should the mixture had been prepared with an activator-to-binder ratio of 0.5 ( 0.54 was used due to flow requirement).

It should be also added that overall, the strength development was faster in fly ash-based mortars than natural Pozzolan-based mortars. This finding can be seen in Figure 4 which shows the ratios of 1 day-to-7 days compressive strengths and 3 days-to-7 days compressive strengths. Alkali-activated natural Pozzolan mortars gained 78, 43, 36, 30, and 34\% of their 7-day strength in 1 day and 92, 78, 81, 70, and 78\% in 3 days for molarities of $2.5,5,7.5,10$, and 12.5 , respectively. For similar molarities, alkali-activated fly ash mortars developed 40, 40, 67, 66, and 78\% of their 7-day strength in 1 day and 91, 86, 99, 91 and 93\% in 3 days, respectively. This observation can also be related to the difference in chemical composition of natural Pozzolan and fly ash (different amounts of silica and alumina). Previous studies showed that the absence of sufficient amounts of aluminum could retard the conversion of Gel 1 (aluminum-rich, Si/Al 1) into Gel 2 (silicon-rich, Si/Al 2), affecting the strength of the resulting product [Pacheco-Torgal et al. 2015]. As Gel 2 is responsible for majority of mechanical strength, hindering its formation could be the reason that natural Pozzolan gained its intrinsic strength slower than fly ash. 
It can also be seen that increases in molarity of activator led to improvements in compressive strength. On average, the 7-day compressive strength of alkali-activated natural Pozzolan mortars increased by 6.6, 8 and 11.4 MPa, when $\mathrm{NaOH}$ concentration increased from 2.5 to 5,5 to $7.5,7.5$ to $10 \mathrm{M}$, respectively. Similar increases in molarity of activator led to averagely 15.3, 6.1, and 3.7 MPa improvements for the alkali-activated fly ash mortars, respectively. The observed improvements can be related to the greater solubility of aluminosilicate in higher $\mathrm{NaOH}$ concentration [Khale and Chaudhary 2007]. Since one of the main steps of geo-polymerization process is the breakdown of aluminosilicates ( $\mathrm{Si}-\mathrm{O}-\mathrm{Si}$ and $\mathrm{Al}-\mathrm{O}-\mathrm{Si}$ bonds) in alkaline environment, higher concentrations led to increased breakdowns. As more aluminosilicates bonds broke down, there were further opportunities for hydrates to be formed, thus increasing the compressive strength.

Both natural Pozzolan- and fly ash-based mortars developed considerably lower strength than those of reference mortars. The ultimate compressive strength (7-day) of $12.5 \mathrm{M}$ alkali-activated mortars were averagely 41 and $51 \%$ lower than 28-day compressive strength of reference I and reference II mixtures, respectively. Although this finding shows that partial use of sodium silicate as an alkaline activator could be inevitable to achieve similar strength to those of Portland cement mixtures, the produced strengths using high $\mathrm{NaOH}$ molarities (7.5M and above) were sufficient for structural applications.

Table 4. Compressive strength of alkali-activated and reference mortars (MPa)

\begin{tabular}{|c|c|c|c|c|}
\hline & $\begin{array}{l}\mathrm{NaOH} \\
\text { Concentration (M) }\end{array}$ & Age (days) & $\begin{array}{l}\text { Natural Pozzolan- } \\
\text { based mortars }\end{array}$ & $\begin{array}{l}\text { Fly ash-based } \\
\text { mortars }\end{array}$ \\
\hline \multirow{15}{*}{$\begin{array}{l}\text { Alkali- } \\
\text { activated } \\
\text { mortars }\end{array}$} & \multirow[t]{3}{*}{2.5} & 1 & 4.6 & 2.1 \\
\hline & & 3 & 5.4 & 4.8 \\
\hline & & 7 & 5.9 & 5.3 \\
\hline & \multirow[t]{3}{*}{5} & 1 & 5.4 & 8.3 \\
\hline & & 3 & 9.7 & 17.8 \\
\hline & & 7 & 12.5 & 20.6 \\
\hline & \multirow[t]{3}{*}{7.5} & 1 & 7.4 & 17.8 \\
\hline & & 3 & 16.5 & 26.5 \\
\hline & & 7 & 20.5 & 26.7 \\
\hline & \multirow[t]{3}{*}{10} & 1 & 9.4 & 20.0 \\
\hline & & 3 & 22.3 & 27.5 \\
\hline & & 7 & 31.9 & 30.4 \\
\hline & \multirow[t]{3}{*}{12.5} & 1 & 10.4 & 27.2 \\
\hline & & 3 & 24.1 & 32.2 \\
\hline & & 7 & 30.8 & 34.7 \\
\hline \multirow{4}{*}{\multicolumn{2}{|c|}{$\begin{array}{l}\text { Reference Portland cement } \\
\text { mortars }\end{array}$}} & Age (days) & Reference I & Reference II \\
\hline & & 3 & 37.8 & 42.8 \\
\hline & & 7 & 46.9 & 52.3 \\
\hline & & 28 & 59.3 & 71.5 \\
\hline
\end{tabular}



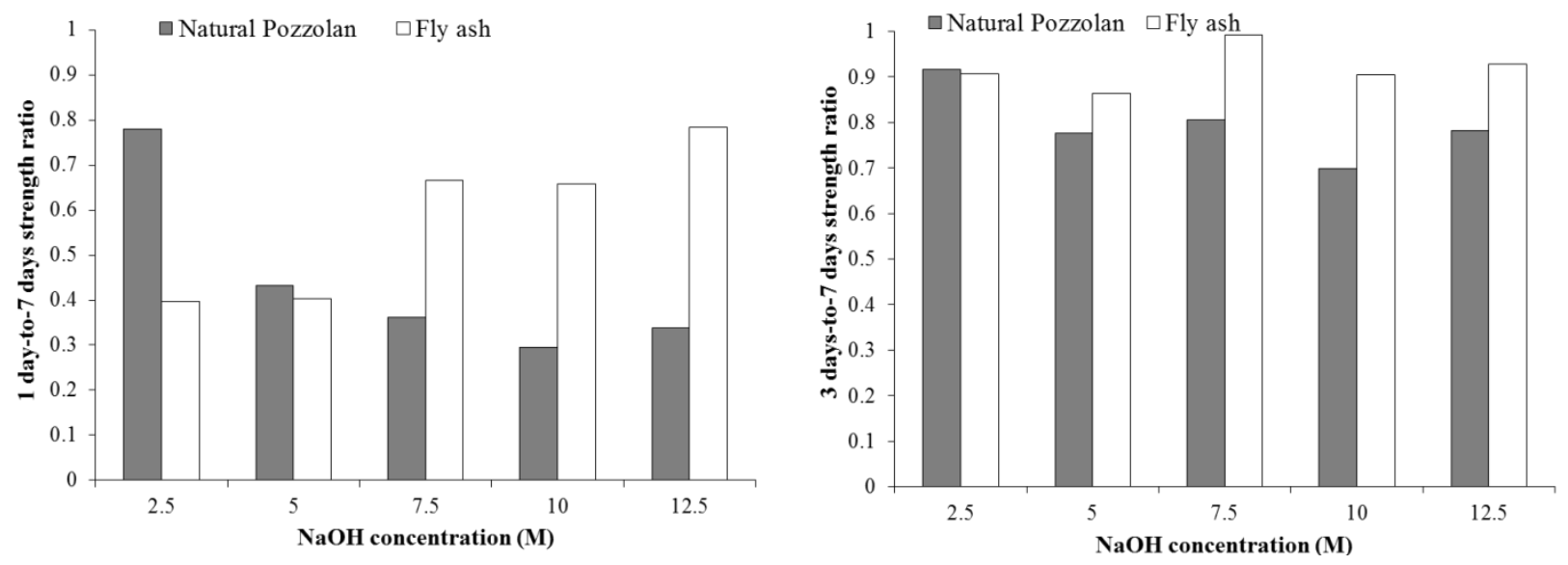

\section{Figure 4. Strength development rate of alkali-activated mortars, (a) 1 day-to-7 days compressive strength ratio, (b) 3 days-to- 7 days compressive strength ratio}

\section{Flexural strength}

Modulus of rupture of the studied alkali-activated mortars was evaluated on the 7-day sealed oven-cured beams. Strain gauges were attached at samples' extreme tension side to measure flexural strains. The obtained stress-strain curve was used to calculate modulus of elasticity of the studied mortars. The modulus of rupture and elastic modulus of alkali-activated mortars are documented in Table 5. Overall, the flexural strength and modulus of elasticity of fly ash- and natural Pozzolan-based mortars were in the same range. Both of these properties increased with increases in $\mathrm{NaOH}$ concentration. Modulus of rupture of alkali-activated natural Pozzolan mortars increased by 108, 123, 15, and 20\% when molarities of solution increased from 2.5 to 5,5 to 7.5 , and 7.5 to 10 , and 10 to 12.5 , respectively. These increases were $210,35,5$, and $13 \%$ for modulus of elasticity, respectively. Increases in molarity of solution from 5 to $7.5,7.5$ to 10 , and 10 to 12.5 led to 32,65 , and $33 \%$ improvements in modulus of rupture, and 13,13 , and $30 \%$ increases in modulus of elasticity of alkali-activated fly ash mortars, respectively.

The flexural strength-to-compressive strength ratio was also calculated and the results are presented in Table 5. In general, this ratio was higher for natural Pozzolan contained mortars than fly ash contained mortars. It varied in the range of 0.22 to 0.30 and 0.16 to 0.27 for alkali-activated natural Pozzolan and fly ash mortars, respectively.

\section{Transport properties}

Initially, absorption, rapid chloride migration and rapid chloride penetration tests were considered for the purpose of this study. It was found that rapid chloride penetration test (RCPT) gives misleadingly high results for this type of alkali-activated materials. Therefore, this section compares only absorption and rapid chloride migration of alkali-activated natural Pozzolan mortars with alkali-activated fly ash mortars and reference Portland cement mortars. These tests were conducted on 7-day alkali-activated and 28-day Portland cement mortar samples.

\section{Absorption}

ASTM C642 was used to determine the absorption and volume of permeable voids of the studied alkaliactivated mortars. Table 6 presents the results of this test. It can be seen that alkali-activated mortars with low molarities exhibited higher absorption and volume of permeable voids than reference mortars, whereas contrary was found for high molarities. Similar to the strength properties, nearly $7.5 \mathrm{M}$ sodium hydroxide was needed for alkali-activated mortars to reach a satisfactory performance (almost same absorption and volume of permeable voids to that of reference Portland cement mortars. Using $\mathrm{NaOH}$ 
concentrations of 10 and $12.5 \mathrm{M}$, alkali-activated natural Pozzolan mortars had lower absorption and volume of permeable voids than alkali-activated fly ash and reference Portland cement mortars.

Figure 5 also shows the absorption of alkali-activated mortars for different molarities. As can be seen, there was an almost linear trend in the results of absorption with increases in molarity of activator. Absorption of natural Pozzolan contained mortars reduced by 17, 26, 49, and $40 \%$ when molarity increased from 2.5 to 5,5 to $7.5,7.5$ to 10 , and 10 to $12.5 \mathrm{M}$, respectively. Similarly, volume of permeable voids significantly reduced with increases in $\mathrm{NaOH}$ concentration. For similar increases in molarity of activator, volume of permeable voids of natural Pozzolan-based mortars decreased by 11, 24, 45 and 6\%, respectively. In case of fly ash-based mortars, increases in $\mathrm{NaOH}$ concentration from 5 to $7.5,7.5$ to 10 , and 10 to $12.5 \mathrm{M}$ led to 13,20 , and $18 \%$ improvement in absorption, and 12,5 , and $4 \%$ reduction in volume of permeable voids, respectively. Higher hydroxide concentration resulted in greater alkaliactivation and a more compact matrix with less voids to allow for moisture penetration (decreased absorption).

Table 5. Flexural strength test results

\begin{tabular}{|l|l|l|l|}
\hline Mix id & $\begin{array}{l}\text { Modulus of } \\
\text { Rupture (MPa) }\end{array}$ & $\begin{array}{l}\text { Modulus of } \\
\text { Elasticity (GPa) }\end{array}$ & $\begin{array}{l}\text { Modulus of } \\
\text { Rupture/Compressive Strength }\end{array}$ \\
\hline N2.5 & 1.33 & 4.33 & 0.23 \\
\hline F2.5 & Not measured & Not measured & -- \\
\hline N5 & 2.77 & 13.43 & 0.22 \\
\hline F5 & 3.30 & 13.87 & 0.16 \\
\hline N7.5 & 6.17 & 18.16 & 0.30 \\
\hline F7.5 & 4.35 & 15.71 & 0.16 \\
\hline N10 & 7.07 & 19.15 & 0.22 \\
\hline F10 & 7.16 & 17.80 & 0.24 \\
\hline N12.5 & 8.49 & 21.55 & 0.28 \\
\hline F12.5 & 9.52 & 23.15 & 0.27 \\
\hline
\end{tabular}

Table 6. Results of absorption test

\begin{tabular}{|l|l|l|}
\hline Mix id & Absorption after immersion (\%) & Volume of Permeable voids (\%) \\
\hline N2.5 & 12.40 & 25.84 \\
\hline F2.5 & Not measured & Not measured \\
\hline N5 & 10.33 & 22.95 \\
\hline F5 & 10.18 & 16.42 \\
\hline N7.5 & 7.70 & 17.47 \\
\hline F7.5 & 8.88 & 14.51 \\
\hline N10 & 3.94 & 9.54 \\
\hline F10 & 7.10 & 13.85 \\
\hline N12.5 & 2.38 & 9.01 \\
\hline F12.5 & 5.86 & 13.32 \\
\hline Reference I & 6.70 & 15.44 \\
\hline Reference II & 7.53 & 16.98 \\
\hline
\end{tabular}




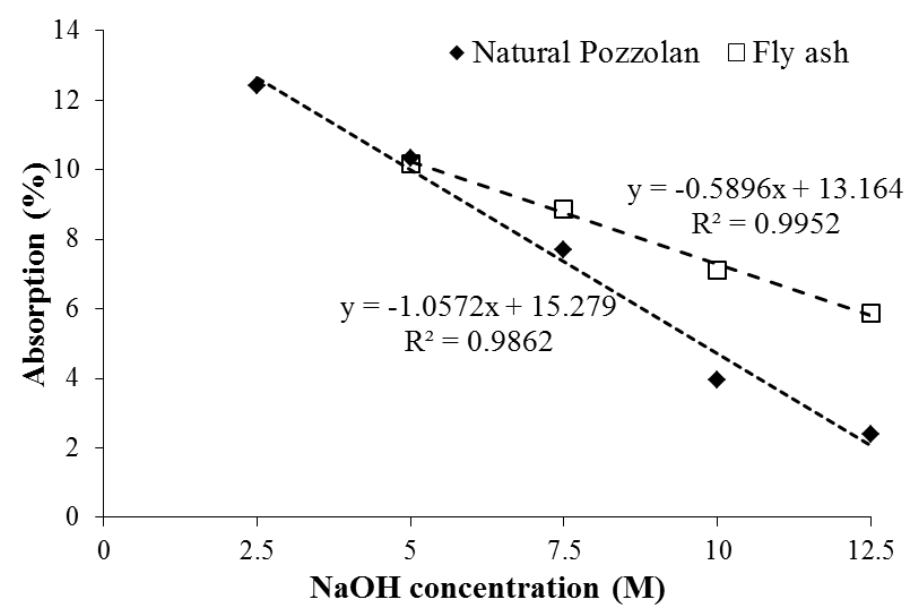

Figure 5. Absorption of alkali-activated mortars

\section{Rapid chloride migration test}

Table 7 documents results of rapid chloride migration test on alkali-activated and reference mortars. It can be seen that chloride penetration, presented as diffusion coefficient and penetrated depth per volt. hour, considerably decreased by increases in molarity of sodium hydroxide. The rate of penetrated chloride for natural Pozzolan-based mortars reduced by 38, 56, 39, and 19\%, when molarity of solution increased from 2.5 to 5,5 to $7.5,7.5$ to 10 , and 10 to $12.5 \mathrm{M}$, respectively. In case of fly ash-based mortars, this rate reduced by 8,13 , and $20 \%$ when molarity increased from 5 to $7.5,7.5$ to 10 , and 10 to $12.5 \mathrm{M}$, respectively.

Similar to the other tested properties, natural Pozzolan required higher molarity to reach an acceptable performance as compared with fly ash. It can be seen that $5 \mathrm{M}$ fly ash-based mortar displayed almost similar results to those of $7.5 \mathrm{M}$ natural Pozzolan-based mortar. For high molarities, performance of alkali-activated natural Pozzolan and fly ash mortars were almost similar. It was also noted that only $12.5 \mathrm{M}$ alkali-activated mortars showed close performance to those of Portland cement mortars.

Table 7. Results of rapid chloride migration test

\begin{tabular}{|l|l|l|}
\hline Mixture id & $\begin{array}{l}\text { Chloride diffusion coefficient } \\
\left(\times 10^{-12} \mathrm{~m}^{2} / \mathrm{s}\right)\end{array}$ & $\begin{array}{l}\text { Rate of chloride penetration } \\
(\mathrm{mm} / \mathrm{Vh})\end{array}$ \\
\hline N2.5 & 194.77 & 0.538 \\
\hline F2.5 & Not measured & Not measured \\
\hline N5 & 112.56 & 0.331 \\
\hline F5 & 32.31 & 0.0986 \\
\hline N7.5 & 41.33 & 0.144 \\
\hline F7.5 & 34.17 & 0.0909 \\
\hline N10 & 21.38 & 0.088 \\
\hline F10 & 26.76 & 0.0795 \\
\hline N12.5 & 15.63 & 0.071 \\
\hline F12.5 & 19.58 & 0.0634 \\
\hline Reference I & 16.05 & 0.0468 \\
\hline Reference II & 16.30 & 0.0475 \\
\hline
\end{tabular}




\section{CONCLUSION}

Based on the results of this study, the following conclusions can be drawn:

- Overall, natural Pozzolan and fly ash proved to be a viable replacement for Portland cement. While the studied alkali-activated mortars yielded considerably lower strength than those of Portland cement mortars, majority of them produced compressive strengths well beyond the required structural compressive strength of $20 \mathrm{MPa}$. The transport properties of alkali-activated mortars having high $\mathrm{NaOH}$ molarity were similar to that of Portland cement mortars.

- The flow of alkali-activated natural Pozzolan mortars was significantly lower than those of alkaliactivated fly ash and Portland cement mortars. The flow of the studied alkali-activated mortars reduced with increases in molarity of sodium hydroxide solution.

- The minimum amount of sodium hydroxide concentration for proper activation was higher for natural Pozzolan mortars than fly ash mortars. While 5M alkali-activated fly ash mortars developed enough strength for structural applications, $7.5 \mathrm{M}$ of sodium hydroxide solution was needed for natural Pozzolan mortars to reach the same level of strength. A similar trend was observed for the transport properties of the studied alkali-activated mortars.

- For low molarity sodium hydroxide solutions (5 and $7.5 \mathrm{M})$, strength of alkali-activated natural Pozzolan mortars were lower than those of alkali-activated fly ash mortars, whereas high molarity alkali-activated mortars $(10$ and $12.5 \mathrm{M})$ produced similar results.

- The strength development rate was faster in alkali-activated fly ash mortars than alkali-activated natural Pozzolan mortars.

- Use of higher $\mathrm{NaOH}$ concentrations led to improved compressive strength, flexural strength, elastic modulus, absorption, volume of permeable voids, and depth of penetrated chloride of the studied alkali-activated mortars.

\section{ACKNOWLEDGEMENTS}

This study was partially funded by NSF Grant \# EPS-0814372 "Nevada Infrastructure for Climate Change Science, Education, and Outreach." Authors would like to thank the National Science Foundation for their support. Thanks are also extended to the Nevada Cement Company for donating natural Pozzolans used in this study.

\section{REFERENCES}

ASTM C109 (2002) Standard Test Method for Compressive Strength of Hydraulic Cement Mortars. ASTM, Philadelphia.

ASTM C1437 (2001) Standard Test Method for Flow of Hydraulic Cement Mortar. ASTM, Philadelphia.

ASTM C305 (1999) Standard Practice for Mechanical Mixing of Hydraulic Cement Pastes and Mortars of Plastic Consistency. ASTM, Philadelphia.

ASTM C311 (2013) Standard Test Methods for Sampling and Testing Fly Ash or Natural Pozzolans for Use in Portland-Cement Concrete. ASTM, Philadelphia.

ASTM C618 (2012) Standard Specification for Coal Fly Ash and Raw or Calcined Natural Pozzolan for Use in Concrete. ASTM, Philadelphia.

ASTM C642 (2013) Standard Test Method for Density, Absorption, and Voids in Hardened Concrete. ASTM, Philadelphia. 
ASTM C78 (2002) Standard Test Method for Flexural Strength of Concrete (Using Simple Beam with Third-Point Loading). ASTM, Philadelphia.

Bondar D, Lynsdale CJ, Milestone NB, Hassani N (2012) Oxygen and chloride permeability of alkaliactivated natural Pozzolan concrete. ACI Materials Journal 109(1):53-62.

Bondar D, Lynsdale CJ, Milestone NB, Hassani N, Ramezanianpour AA (2011a) Effect of type, form, and dosage of activators on strength of alkali-activated natural pozzolans. Cement and Concrete Composites 33:251-260.

Bondar D, Lynsdale CJ, Milestone NB, Hassani N, Ramezanianpour AA (2011b) Engineering properties of alkali-activated natural Pozzolan concrete. ACI Materials Journal 108(1):64-72.

Duxson, P., Fernandez-Jimenez, A., Provis, J.L., Lukey, G.C., Palomo, A. and van Deventer, J.S.J. (2007a) 'Geopolymer technology: the current state of the art', J Mat Sci, 42(9), 2917-2933.

Fernandez-Jimenez A., Palomo A. and Alonso M.M. (2005b), 'Alkali activation of fly ashes: mechanisms of reaction', in Congress of Non-Traditional Cement and Concrete II, Ed. V. Bilek and Z. Kersner, Brno University of Technologie, 1-12.

Fernandez-Jimenez, A., Palomo, A. and Lopez-Hombrados, C. (2006) Engineering properties of alkaliactivated fly ash concrete, ACI Mater Journal, 103(2), 106-112.

Glukhovsky V.(1994) Ancient, modern and future concretes, First Inter. Conf. Alkaline Cements and Concretes, Kiev, Ukraine, 1, 1-8.

Haddad R.H., Alshbuol O. 2016. Production of geopolymer concrete using natural pozzolan: A parametric study. Construction and Building Materials 114, 699-707.

Huntzinger, D.N. \& Eatmon, T.D. 2009. A life-cycle assessment of Portland cement manufacturing: comparing the traditional process with alternative technologies. Journal of Cleaner Production, 17, 668-675.

Ismail I., Bernal S.A., Provis J.L., Nicolas R.S., Hamdan S., van Deventer J.S.J. 2014. Modification of phase evolution in alkali-activated blast furnace slag by the incorporation of fly ash. Cement and Concrete Composites 45, 125-135

Khale D., Chaudhary R. (2007) Mechanism of geopolymerization and factors influencing its development: a review. Journal of Materials Science 42:729-746.

Lemougna PN, MacKenzie KJD, Melo UFC (2011) Synthesis and thermal properties of inorganic polymers (geopolymers) for structural and refractory applications from volcanic ash. Ceramics International 37(8):3011-3018.

Lorenz, W., 1985 The use of volcanic rocks as construction raw material, Natural Resources and Development, 22, 7-24.

NT BUILD 492 (1999) Concrete, mortar and cement-based repair materials: chloride migration coefficient from non-steady-state migration experiments. NORDTEST.

Pacheco-Torgal F, Labrincha J, Leonelli C, Palomo A, Chindaprasit P (2015) Handbook of AlkaliActivated Cements, Mortars and Concretes. Elsevier, Woodhead publishing series in civil and structural engineering.

Pacheco-Torgal F., Castro-Gomes J., Jalali S. 2008. Alkali-activated binders: A review: Part 1. Historical background, terminology, reaction mechanisms and hydration products. Construction and Building Materials 22(7), 1305-1314. 
Pacheco-Torgal, F., Abdollahnejad, Z., Camões, A.F., Jamshidi, M. \& Ding, Y. 2012. Durability of alkali-activated binders: A clear advantage over Portland cement or an un-proven issue?. Construction and Building Materials, 30, 400-405.

Palomo A, Grutzeck MW, Blanco MT (1999) Alkali-activated fly ashes A cement for the future. Cement and Concrete Research 29:1323-1329.

Palomo A., Fernadez-Jimenez A. and Kovalchuk G., (2005), Some key factors affecting the alkali activation of fly ash, 2nd International Symposium of Non-Traditional Cement and Concrete, Brno, Czech Republic.

Sam (2015) "Why do some volcanoes erupt after being dormant?" <http://samanthagouldson.com/whydo-some-volcanoes-erupt-after-being-dormant-2/>

Shi C., Fernandez-Jimenez A. and Palomo A., (2011) New cements for the 21st century: the pursuit of an alternative to Portland cement, Cem Concr Res, 41, 750-763. 